\title{
BANKANIN MÜŞTERILERININ SIRLARINI SAKLAMA YÜKÜMLÜLÜĞÜNÜN SINIRLARI
}

\author{
Emin Cem KAHYAOĞLU*
}

\section{$\ddot{O z e t}^{* *}$}

4389 sayll Bankalar Kanununun 22. maddesinin 8. fikrasinda bankanın müşterilere ait sırları saklama yükümü özel olarak düzenlenmiştir. Anılan maddeye göre müssteri sırlarını saklamakla yükümlü olanlar, bankaların mensupları ve diğer görevlileri ile üçüncü kişilerdir.

Bankalar müşteri sırlarını içeren bazı faaliyetleri ile ilgili olarak bir kısım işlerin ifası amacıyla üçüncü kişilerden yararlanabilirler. Hatta kredi kartlarinın ve ekstrelerinin basimı, bankanin faaliyetleri ile ilgili yazılımların ve programların hazırlanması gibi işlerin uzman üçüncü kişilere yaptırılması günümüz koşullarında banka bakımından bir zorunluluk oluşturmaktadır. Bu durumda üçüncü kişilerin ifa yardımcısı olarak nitelendirilebilmeleri mümkündür.

Tüm bu işlemlerin yerine getirilmesi sırasında, bankanın müşterilerine ait bazı bilgilerin anılan kişilere yapacakları iş ile sınırlı olarak verilmesi kaçınılmazdır. Ancak bilgilerin yapılan is gereği yapan tarafindan ögrenilmesi, strların banka tarafindan açıklanması anlamını taşımamaktadır.

İfa yardımcıları, ilgili madde metninde anılan "diğer görevliler" kapsamında kabul edilmelidir. Müşteri sırlarının banka mensupları tarafindan da açıklanması mümkün olduğundan, kredi kartı bilgilerinin basım amacıyla üçüncü kişilere verilmesi, bankanın sırların açıklanması riskini üstlenmesi olarak değerlendirilmelidir.

*Yrd. Doç. Dr., Bahçeşehir Üniversitesi Hukuk Fakültesi

${ }^{* *}$ For the summary in English, see the end page of the article. 


\section{Genel Olarak}

4389 say1lı Bankalar Kanununun 22. maddesinin 8. fikrasında', "Bankaların mensupları ve diğer görevlileri, sıfat ve görevleri dolayısıyla ögrendikleri bankalara veya müşterilerine ait sırları bu konuda kanunen açıkça yetkili kılınan mercilerden başkasına açıklayamazlar. Bu yükümlülük görevden ayrılmalarından sonra da devam eder. Bu madde hükmüne aykırı davrandığı tespit edilen kişiler için bir yıldan üç yıla kadar ağır hapis ve bir milyar liradan az olmamak üzere ağır para cezasına hükmolunur. Banka ve müşterilerine ait sırları açıklayan üçüncü kişiler hakkında da aynı cezalar uygulanır" hükmüne yer verilmektedir.

Aynı fikrada, "kredilerin takip ve kontrolü için, ana faaliyet konuları para ve sermaye piyasaları ile sigortacılık olan ve bu konularda özel kanunlarına göre alınan izin ve ruhsat ile faaliyet gösteren mali kurumlar ile Kurum tarafından uygun görülecek şirketler arasında müşterileri ile ilgili olarak doğrudan doğruya veya en az on kurum tarafından kurulacak şirketler vasıtasıyla yapılacak bilgi alışverişi bu hükmün dışında" bırakılmakta, böylece tanımlanan şirketler arasında müşterileri hakkında bilgi alışverişine olanak tanınmaktadır. Bu hükmün "sır saklama" yükümüne, sınırlı amaçla ve kapsamda da olsa bir istisna getirdiği açıktır.

Diğer taraftan, bankaların mensuplarının, diğer görevlilerinin ve üçüncü kişilerin, bankalara ve banka müşterilerine ait sırları saklamakla yükümlü bulundukları, banka ve müşterileri hakkındaki bilgileri sadece kanunen yetkili kılınmış mercilere açıklayabilecekleri, bu yükümlülüğe uyulmaması halinde uygulanacak cezai yaptırıma da aynı fikra metninde yer verilmiştir.

Aşağıda kişiliğin korunması kavramından da hareket ile müşteri sırrı , kimlerin sir saklama yükümlülüğüne tabi oldukları, bu yükümlülüğün kapsamı ve istisnaları üzerinde durulacak, özellikle bankalann faaliyetleri ile ilgili olarak, faaliyetin özü ile ilgili olmamak kaydı ile bir kısım yan hizmetleri üçüncü kişilerden almak istemeleri ya da ihtiyacında bulunmaları halinde bu konudaki bağlantılarının sır saklama yükümünün ihlalini teşkil edip etmeyeceği tartışılacaktır. 


\section{Kişiliğin Korunması Kavramı}

Bankalar Kanununda yer verilen hükmün ve sır saklama yükümünün incelememiz bakımından sınırlarının belirlenebilmesi için, öncelikle daha genel bir kavram olan kişilik hakkı ve kişilik haklarının korunmasına kısaca işaret etmekte yarar görmekteyiz.

1982 Anayasasının 17/1 ve 20/1 maddeleri hükümlerinde yer alan, kişinin maddi ve manevi varlığını koruma ve özel hayatın gizliliği ve korunması ilkeleri ile kişiliğin korunmasına işaret edilmektedir.

Medeni Kanunun 23-26. maddelerinde, Borçlar Kanununun 41, 48 ve 49. maddelerinde ve Ticaret Kanununun 56 vd. maddelerinde de kişiliğin korunmasına ilişkin düzenlemeler vardır. Anılan hükümler gibi, 4389 sayılı Bankalar Kanununun 22/8 maddesi de, kişiliğin korunmasının özel bir hali olan müşteri sırlarının korunmasını düzenlemektedir.

Kişinin özel hayatı ve buna ait özellik ve sırlar, medeni hukukun genel esasları uyarınca, hukuken korunan varlıklarından ve kişisel menfaatlerindendir.Medeni Kanunun 23 ve 24 . maddeleri kişiliğin korunmasında genel ilkeleri düzenlemektedir. MK. m. 23'de kişiliğin hukuki işlemle tecavüze karşı korunması, MK. m. 24'de kişiliğin haksız müdahalelere karşı korunması hüküm altına alınmıştır².

Kişilik hakkı kapsamında yer alan değerler sınırlı sayıda olmayıp gelişen teknoloji, ihtiyaçlar karşısında her gün genişleyen esnek bir yapıya sahip bulunmaktadır. Kişinin mali ve iktisadi durumu, kişi ile ilgili malvarlı̆̆ bilgilerinin de kişilik hakkı kapsamında korunmaya değer bulunduğu artık tartışmasızdır.

\section{Bankanın Müşterilere Ait Sırları Saklama Yükümü}

Yukarıda kısaca işaret edildiği üzere kişinin mali durumu, borçlanı, kişi ve malvarlığı hakkındaki bilgileri kişilik hakkı kapsamında korunmaya değer bulunduğu için, 4389 sayılı Bankalar Kanununun 22. maddesinin 8. fikrasında , kişilik hakkının korunmasının bir görünümünden ibaret bulunan, bankanın müssterilere ait sırları saklama yükümü, ihlali halinde ağır ve telafi edilemeyecek zararlara neden olabileceğinden, özel olarak düzenlenmiştir. 
Bankalar Kanunu hükümlerinde müşteri sırn kavramı tanımlanmamış ise de müşteri sırn, ilgilinin iradi veya gayri iradi olarak bankaya verdiği veya bankanın mesleğini icra ederken öğrendiği bilgilerin açıklanmamasına ilişkin, dürüstlük kuralından kaynaklanan bir yükümdür ${ }^{3}$. Bu, çoğu zaman sözleşmeden kaynaklanan, ancak tanımda da belirtildiği üzere, dayanağını dürüstlük kuralında bulan bir asli yükümlülüktür. Bankanın müşterileri ile olan ilişkilerinde, sözleşme öncesi ve sonrası elde ettiği tüm bilgiler, müşterinin nakit veya mal varlığı durumu, hatta işlemleri ile ilgili talimatlan, ailesine ilişkin bilgiler, kredi itibarı, yatırım faaliyetleri, kar ve zarar hesaplan, müşterinin mesleki yetenek ve ödeme gücü hakkında varmış olduğu genel değer yargısı, bankanın müşteri sırn kavramına girmektedir. Banka ile kredi ilişkisi içinde olan kişiler, mevduat sahipleri veya bankada kiralık kasaları bulunanlar gibi banka müşterileri hakkındaki tüm bilgi ve belgeler müşteri sırn kapsamındadırlar ${ }^{4}$.

Günümüzde özellikle kredi kartları, tüketici kredileri, konut ve oto kredileri sağlayan kuruluşlar, müşterilerinin mali durumlan, mal varlıkları hakkında geniş bilgilere sahiptirler. O kadar ki, bu bilgilerin bir kısmı, banka müşterisinin yakınları tarafından dahi bilinmeyen ya da müşteri tarafından yakınlarına dahi açıklamak istemediği, gizli tuttuğu bilgilerden olabilir. Müşterilerle ilgili bu bilgiler depolanmakta, müşteri ile ilişkiler sona erse dahi muhafaza edilebilmektedir. Hatta bu bilgi ve verilerin ticari meta olarak kullanılabilmesi ihtimali yüksektir. Depolanan bu bilgilerin üçüncü kişilere aktarılması, çeşitli şekillerde açıklanması, ticari bir amaç izlenmese dahi müşteri sırlarına saldırı teşkil edebilecektir. İşte Bank. m. 22/8, bankalar bakımından, banka ve müşteri sırlanının açıklanması durumunda özel olarak cezai yaptırımlar öngörmektedir.

Ancak hemen ifade edelim ki, cezai yaptırımların yanı sıra sır saklama yükümünün ihlali nedeniyle meydana gelebilecek zararların tazminini talep, genel düzenlemeler çerçevesinde mümkündür.

\section{Sır Saklama İle Yükümlü Olanlar}

Müşteri sırlarını saklamakla yükümlü olanlar, Bankalar Kanununun 22/8. maddesine göre, bankaların mensupları ve diğer görevlileri ile üçüncü kişilerdir. Banka mensup ve diğer görevlilerinin sır saklama yükümü , görevden ayrıldıktan sonra da devam edecektir. 
Diğer görevlilere, Merkez Bankası yetkilileri, resmi görevi sonucu banka ile ilişki kuran devlet memurlan, noter, icra memuru, müfettiş, yeminli denetçi, bağımsız denetçi, hesap uzmanı, kanunen yetkili kılınıp da bankadan bu sırlan görevleri gereği öğrenen kişi ya da merciler girer ${ }^{5}$.

Burada üzerinde özellikle durulması gereken husus, bankaların müşteri sırlarını içeren bazı faaliyetleri ile ilgili olarak bir kısım işlerin ifası amacıyla üçüncü kişilerden yararlanıp yararlanamayacaklandır. Hemen belirtelim ki, bankaların bu amaçla üçüncü kişilerden yararlanmak istemeleri, üçüncü kişilerle hukuki ilişki içine girmeleri halinde, bu kişilerin ifa yardımcısı şeklinde nitelendirilebilmeleri mümkündür (BK. m. 100) ${ }^{6}$.

Banka ve üçüncü kişi arasındaki hukuki işlem genellikle iş görme sözleşmeleri grubuna dahil bir sözleşme olarak karşımıza çıkmaktadır. Ancak hemen ifade edelim ki, burada taraflar arasındaki sözleşmelerin niteliği bir önem taşımamakta, bankanın müşteri sırlarını içeren faaliyetlerini kısmen ya da tamamen ifa yardımcısına bırakıp bırakamayacağının değerlendirilmesi gerekmektedir.

Bir borcun ifasında ifa yardımcısı kullanılabilmesi için, bu durumun borca aykırılık teşkil etmemesi gerekmektedir. Borcun bizzat borçlu tarafından ifasında alacaklının menfaati bulunmadıkça, borcun üçüncü şahıs tarafından dahi ifası mümkündür. $\mathrm{O}$ kadar $\mathrm{ki}$, alacaklının üçüncü şahsın ifasını kabul etmemesi halinde, alacaklı temerrüdünden de bahsolunabilecektir. İfa yardımcısı kullanılabilmesi için borçlunun nıası hem zaruri hem de kafidir. İfa yardımcısı kullanılan hallerde borcun üçüncü şahıs tarafından ifası söz konusu olmamakta, ifa yardımcısı borcun ifasına çeşitli şekillerde katılmaktadır. Nitekim bir akreditif ilişkisinde muhabir bankanın ifaya katılmasında ifa yardımcısı niteliği mevcuttur. Diğer taraftan, ifa yardımcısının bir gerçek ya da tüzel kişi olması da mümkündür ${ }^{7}$. İfa yardımcısının alacaklının bir müstahdemi ya da alacaklı ile arasında bir hukuki ilişki bulunan kişi olması da mümkün bulunmaktadır. Borçlunun kredi kartı ödemelerinin kabulü için alacaklı bankanın diğer bankalar ile anlaşma yaptı̆̆ 1 durumda, ödemeleri diğer banka şubelerinin de kabul etmesi, bu ihtimalin bir örneğini teşkil eder.

Banka müşterisinin kendisine ait sırları ancak güven duyduğu banka ya da bankalara verdiği de bir gerçektir. Müş̧teri, sırlarının gizli tutulacağı, üçüncü kişilere açıklanmayacağı inancını taşımaktadır. Bunun yanı sıra ilerleyen teknoloji, işlemlerde sürat ve uzmanlaşma da çağımızın 
gerçeklerindendir. Her kuruluş gibi bankalar da bir kısım işlerin görülmesini, alanlarında uzmanlaşmış kişi ya da kuruluşlara bırakmayı, böylelikle sürat ve emniyetin yanı sıra daha iyi hizmet vermeyi amaçlamaktadırlar. Uygulamada en çok karşılaşılan sorun, çok sayıdaki müşteri için kredi kartlarının ve ekstrelerinin süratle bastırılması ve zamanında müşterilere ulaştırılmasında karşılaşılan güçlüklerdir. Kredi kartlarının basımının özel bir teknolojiyi, bilgiyi ve uzmanlığı gerektirdiği tartışmasızdır. Bunun gibi kredi kart ekstrelerinin basımında, ihtiyaç duyulan sürat ve düzenin sağlanması bakımından özel bir uzmanlığa ihtiyaç gösterdiği kabul edilmektedir. $\mathrm{Bu}$ açıklamalar sadece kredi kartları müşterileri ile sınırlı olmayıp, bankanın diğer müşteri hizmetleri bakımından da geçerli olabilir. Nitekim bir bankanın faaliyetleri ile ilgili yazılımlar, programlar hazırlanmasında, hatta sürekli bakım ve destek hizmetlerinde, uzman üçüncü kişilerle anlaşmalar yapılması, bu kişilere ihtiyaca uygun yazılımlar hazırlattırılarak uygulamaya konulması, bakım ve destek hizmetlerinin alınması zorunluluğu tartışmasızdır.

Tüm bu iş ve işlemlerin yerine getirilmesi sırasında, bankanın müşterileri ve bu müşterilere ait bazı bilgilerin anılan kişilere yapacakları iş ile sınırlı olarak veriłmesi kaçınılmazdır. Gerçektende bir bilgisayar programı hazırlayan ve bankanın ihtiyacına cevap vermek amacıyla çalışan uzman kuruluşlar, özel şirketler, programın yapımında ve hayata geçirilmesinde belki de müşterilere ait tüm bilgileri öğrenebilme imkanına sahip bulunmaktadır. Ancak bu durum uzman kuruluşun işi yapabilmesinin bir gereğidir. Bunun gibi kredi kartı ve /veya ekstrelerin basımında da kısmen de olsa, uzman kuruluşun, müşterinin adresini, alışveriş yaptı̆̆ 1 yerleri, harcamaları ve belki de mevduat, hesap numarasını görebilmesi mümkündür. Kanatimizce, bu bilgilerin yapılan iş gereği yapan tarafından öğrenilebilmesi imkanının olması, sırların banka tarafından açıklanması anlamını taşımamaktadır. Bankanın müşterilerine ait sırları açıklama iradesi bulunmadığı gibi, mal varlığı değerleri, hesap hareketleri gibi tüm kayıtlar, temel bilgiler ve muhasebe bankada kalmakta, bilgiler bir başka kuruluşta depolanmamakta, işlem bitiminde imha edilmektedir. Teknolojinin sağladığı imkanlar ile sırf kredi kartı ekstresi içeriği, o döneme iliş̧in olarak çeşitli vasıtalarla iletilmekte, sadece kredi kartı ya da ekstrenin basımı bu kişilerce gerçekleştirilmektedir.

Doktrinde ${ }^{8}$, bankaların bazı işleri "outsource etmesi" nin, bu nedenle müşterilere ait bilgileri üçüncü şahıslara vermesinin, sır saklama yükümünün ihlalini oluşturduğu yolunda bir görüş mevcut ise de, 
yukarıdaki açıklamalar çerçevesinde bu görüşe katılamamaktayız. Kaldı ki, ifa yardımcılarının Bankalar Kanununun 22. maddesinin 8. fikrasında yer verilen diğer görevliler kapsamında mütalaa edilmesi gerektiği kanaatini taşımaktayız. Müşteri sırlarının banka mensupları tarafından da açıklanması mümkün olduğundan, kredi kartı veya ekstrelerle ilgili bilgilerin basım amacıyla üçüncü kişilere verilmesi, bankanın anılan riski üstlenmesi olarak değerlendirilmelidir.

\section{Sır Saklama Yükümüne Aykırılığın Sonuçları}

Bankanın müşterisine ait sırları saklama yükümüne aykırılığı halinde banka ve/veya açıklayan kişilerin hukuki ve cezai sorumluluklarına gidilebilir.

\section{Hukuki sonuçlar}

Sır saklama yükümünün ihlali, banka ile müşteri arasındaki sözleşmenin müspet ihlalini oluşturduğu için, banka, kusuru bulunmadığını ispat etmedikçe müşterinin müspet zararını tazmine mecbur olur ( BK. m. 96$)^{9}$.

Yükümün ihlali ayrıca, müşteri bakımından sözleşmeyi fesih için bir haklı sebep oluşturabilir ${ }^{10}$.

Müşterinin açabileceği tazminat davalarına, akde aykırılık, yardımcı şahıslardan sorumluluk ( BK. m. 100 ), haksız fiil ( BK. m. 41 ), istihdam edenin sorumluluğu ( BK. m. 55 ), manevi tazminat ( BK. m. 49 ) hukuki dayanak oluşturabilir ${ }^{11}$.

\section{Cezai sonuçlar}

BanK. m. 22/8'e göre, sır saklama yükümünü ihlal eden banka mensupları, diğer görevlileri ve üçüncü kişiler hakkında bir yıldan üç yıla kadar ağır hapis ve bir milyar liradan az olmamak üzere ağır para cezası uygulanır.

\section{Sır Saklama Yükümünün İstisnaları}

Bunları üç başlık altında toplayabiliriz. 


\section{Müşterinin onayı}

Müșteri, kullandığ1 krediler gibi, kendisini ilgilendiren bilgilerin üçüncü kişilere açıklanması konusunda bankasına yetki verebilir ${ }^{12}$.

Müşteri, bankanın hangi bilgileri verebileceğini belirleyebilir. Müşterinin izin verdiği kişi ve kuruluşlara izin çerçevesinde bilgi verilmesi yükümün ihlali sayılmaz. Örnek olarak, 'evlilikte mal ayrılığı rejiminde, bankaya talimat verilerek eșe bilgi alma hakkı tanınabilir.

\section{Kanunen yetkili kılınan mercilerin talebi}

Banka, kanunen yetkili k1lınan mercilere, onların istediği bilgileri vermek zorundadır(BanK. m. 22/8). Bu şekilde sir saklama yükümüne aykırı hareket edilmiş olsa bile banka sorumlu tutulmaz. Ancak verilen bilginin, yetkili merciinin öğrenmek istediği konu veya konularla sınırlı olması gerekir. Aksi taktirde, yani banka istenilenden fazla bilgi verdiği durumda yine sorumlu tutulur ${ }^{13}$.

Hangi mercilerin bankalardan müşterileri ile ilgili bilgi almaya yetkili oldukları mevzuatta belirlenmiştir. Örnekler vermek gerekirse; Adalet Bakanlığı Teftiş Kurulu Tüzüğüne göre Adalet Bakanlığı müfettişleri; T.C. Merkez Bankası Kanununa göre Başbakanlıkça belirlenecek bağımsız denetim kuruluşları; Avukatlık Kanununa göre "görevlerinin yerine getirilmesi” ile sınırlı olarak avukatlar; Bankalar Kanununa göre Bankacilık Düzenleme vè Denetleme Kurulu, Tasarruf Mevduatı Sigorta Fonu, bankalar yeminli murakıpları; Borçlar Kanununa göre özel vekaletname ibraz eden vekil, müteselsil borçlu, ortak hesaplarda hesap sahiplerinden her biri, kefil, adi şirket ortağı; İ́cra ve İflas Kanununa göre icra ve iflas daireleri; Rekabetin Korunması Hakkında Kanuna göre Rekabet Kurulu; Sermaye Piyasası Kanununa göre Sermaye Piyasası Kurumu uzman ve uzman yardımcıları; Medeni Kanuna göre mal birliği ve mal ortaklığı rejimlerinin kabulü halinde eş, veli, vasi, kayyım, kanuni müşavir, kanuni mirasçı, mansup mirasçı, intifa hakkı sahipleri, hapis hakkı sahipleri; Ticaret Kanununa göre kollektif ortaklar, anonim ortaklıkta Ticaret Bakanlığı müfettişleri, tasfiye memurları, bankalardan müşterileri hakkında bilgi almaya yetkili kılınmışlardır ${ }^{14}$. 


\section{Mali kurumlar arasında yapılacak bilgi alı̧verişi}

BanK. m. 22/8'in son cümlesi ile mali kurumların kredi müşterileri hakkında istihbarat alışverişini gerçekleştirmeleri için şirketler kurmalarına izin verilmiştir. Anılan hükme göre, en az on mali kurum, örneğin banka, şirket kurarak bu fonksiyonu yerine getirebilirler. Bu şekilde kurulacak bir şirket, sadece kuruculara değil tüm mali kurumlara müşterileri ile ilgili bilgi verebilecektir. Gerçekten, kredi almak için başvuran kişilerin, kredi verilebilir olup olmadıklarını belirlemek için bu tür istihbarat çalışmalarına ihtiyaç vardır.

$\mathrm{Bu}$ şekilde müşteri sırrının açıklanması yasağına istisna getirilirken sadece bankalar arası değil, aynı zamanda mali kurumlar arası bilgi alışverişine izin verilmiştir. Fıkra metnine göre bunlar, "ana faaliyet konuları para ve sermaye piyasalan ile sigortacilık olan ve bu konularda özel kanunlarına göre izin ve ruhsat ile faaliyet gösteren kurumlardır”.

Özel bir izin ve ruhsat ile faaliyet gösteren mali kurumlar, finansal kiralama şirketleri, özel finans kurumları, sermaye piyasası aracı kurumları, risk sermayesi kuruluşlan, yatırım danışmanlığı kuruluşlanı, finansman şirketleri, genel finans ortaklıkları, yatırım ortaklıkları, factoring şirketleri ve yetkili müesseselerdir ${ }^{15}$.

T.C. Merkez Bankası bünyesinde kurulu bulunan risk merkezi de bankaların, müşterilerinin kredi kartı talepleri aşamasında başvurdukları bir istihbarat kaynağı haline gelmiştir ${ }^{16}$.

\section{Summary}

The obligation of banks to keep the secrets of its clients has been provided for in Art. 22(8) of the Banking Act No 4389. According to the aforementioned Article, those who are under this obligation are the personnel of the bank, the other entitled persons and third persons.

Banks may make use of the services of third persons in their activities regarding secrets of their clients. It is especially inevitable for banks to make use of the services of third persons in activities such as having credit cards and extracts printed and the preparation of programs and software. It is possible to accept such third persons as those who assist fulfilling the obligations. 
During all these processes, it is inevitable to supply these persons with information regarding bank clients within strict limits, necessitated by the services they will perform. The provision of information to such persons does not mean that the bank revealed its clients' secrets. Those who assist fulfilling the obligations, must be considered within the scope of the concept "the other entitled persons". Since it is a fact that clients' secrets may also revealed by banks' personnel, the provision of information regarding credit cards to third persons means that the bank accepts the risk of disclosure of secrets.

\section{Sonnotlar}

${ }^{1}$ Bugün yürürlükte olan 4389 sayılı Bankalar Kanununun 22. maddesinin 8 . fikrası,3182 sayılı Kanunun 83. maddesi karşılığıdır.

2 Oğuzman / Seliçi /Oktay, Kişiler Hukuku, İstänbul 1999 , s. 1115 vd. ; İmre, Şahsiyet Haklarından Şahsın Özel Hayatının ve Gizliliklerinin Korunmasına İlişkin Meseleler, İstanbul Hukuk Fakültesi Mecmuası, C. XXXIX, S. 1-4, s. 147 vd.; Arpacı, Kişiler Hukuku, 2. Bası, İstanbul 2000, s. 143 vd.; Şen, Özel Hayatın Gizliliği ve Korunması, İstanbul 1996, s. 5 vd.

${ }^{3}$ Tekinalp , Banka Hukukunun Esaslanı, İstanbul 1988, s. 296; Altop , Türk, İsviçre ve Alman Hukuklarında Bankaların Verdikleri Banka Bilgilerinden Dolayı Hukuki Sorumluluklanı , İstanbul 1996 , s. 40 vd.; Taşdelen , Bankalar Kanunu Şerhi, Ankara 2002, s. 651 vd.

4 Reisoğlu , Bankalar Kanunu Şerhi , 5. Bası, Ankara 2002, s. 1149 vd.

5 Reisoğlu , (2002), s. 1153; Taşdelen, (2002), s. 654.

6 Altop, (1996), s. 108.

7 Oğuzman / Öz , Borçlar Hukuku Genel Hükümler , 2. Bası, İstanbul 1998, s. 350 .

8 Taşdelen, (2002), s. 655.

9 Tekinalp ,(1988), s. 299 ; Reisoğlu , (2002), s. 1155; Altop , (1996), s. 59.

10 Tekinalp, (1988), s. 300.

${ }^{11}$ Reisoğlu , (2002), s. 1155; Altop, (1996), s. 60. 
12 Reisoğlu , (2002), s. 1155; Altop, (1996), s. 51; Taşdelen, (2002), s. 653.

13 Tekinalp, (1988) , s. 300.

${ }^{14}$ Ayrıntılı bilgi için bakınız: Reisoğlu, (2002), s.1157 vd.; Taşdelen, (2002), s. 656 vd.

15 Reisoğlu , (2002), s. 1200 vd.; Tekinalp, (1988), s. 301.

${ }^{16}$ Reisoğlu , (2002), s. 1202. 